\title{
Papers
}

\section{Promoting walking and cycling as an alternative to using cars: systematic review}

David Ogilvie, Matt Egan, Val Hamilton, Mark Petticrew

\begin{abstract}
Objectives To assess what interventions are effective in promoting a population shift from using cars towards walking and cycling and to assess the health effects of such interventions.

Data sources Published and unpublished reports in any language identified from electronic databases, bibliographies, websites, and reference lists.

Review methods Systematic search and appraisal to identify experimental or observational studies with a prospective or controlled retrospective design that evaluated any intervention applied to an urban population or area by measuring outcomes in members of the local population.

Results 22 studies met the inclusion criteria. We found some evidence that targeted behaviour change programmes can change the behaviour of motivated subgroups, resulting (in the largest study) in a shift of around $5 \%$ of all trips at a population level. Single studies of commuter subsidies and a new railway station also showed positive effects. The balance of best available evidence about publicity campaigns, engineering measures, and other interventions suggests that they have not been effective. Participants in trials of active commuting experienced short term improvements in certain measures of health and fitness, but we found no good evidence on effects on health of any effective intervention at population level.

Conclusions The best available evidence of effectiveness in promoting a modal shift is for targeted behaviour change programmes, but the social distribution of their effects is unclear and some other types of intervention have yet to be rigorously evaluated.
\end{abstract}

\section{Introduction}

Driving cars contributes to traffic congestion, air pollution, and the risk of injury and death to road users, whereas walking and cycling pose little risk to others and provide opportunities for physical activity. ${ }^{1}$ Increasing physical activity in the population has been described as the "best buy" for improving public health, ${ }^{2}$ but we have tended to promote physical activity as leisure and through individual behaviour change. ${ }^{3}$ Could we also achieve this through changes in the transport environment?

Shifting people's approach to transport is now a common objective of transport policies, the overall aims of which may include managing congestion and improving air quality, road safety, and access to services. Various interventions have been advocated or implemented, but evidence of the actual effects of proposed measures is rarely cited, and we cannot assume that apparently sensible measures will be effective or free from harm- ful effects. ${ }^{4-8}$ To date, systematic reviews have tended to concentrate on relatively narrow questions about safety. ${ }^{9}$ We carried out a systematic review of the best available evidence on the effects of population level interventions to promote a shift from using cars towards walking and cycling.

\section{Methods}

We searched electronic databases and websites, bibliographies, reference lists, and our own archives for published and unpublished documents in any language, combining groups of search terms representing cars, walking or cycling, and a change in mode of transport (see bmj.com for further details of methods). We then invited experts to contribute additional references.

We included controlled or uncontrolled prospective studies and controlled retrospective studies of urban population or area level interventions in which outcome measures included changes in the distribution of choice of mode of transport among local people. We also sought evidence of effects on health and data on the distribution of effects between social groups. We assessed studies against 10 common validity criteria based on existing checklists (see table A on bmj.com). ${ }^{10-12}$

The interventions, study designs, and outcome metrics used were heterogeneous (see table B on bmj.com). Formal statistical synthesis was not possible, but for some studies we were able to summarise effects using a common metric: the absolute percentage share of all trips that were shifted from cars to walking and cycling combined (box).

\section{Results}

We screened 5606 references and assessed the full text of 399 documents in seven languages (see figure on bmj.com). Twenty two studies met our inclusion criteria: three randomised controlled trials, seven non-randomised controlled prospective studies, 11 uncontrolled prospective studies, and one controlled retrospective study. We categorised studies according to the main focus of the intervention assessed. Within each intervention category, we have reported interventions in decreasing order of overall study validity, citing results of statistical tests if authors reported them or if we could estimate confidence intervals from reported data (table). Additional data can be found in table $\mathrm{C}$ on bmj.com.

Details of the search strategy and study selection, references to primary studies included in the review (w1-w51), five tables of study data, and a flow chart can be found on bmj.com 
Summary of evidence of effectiveness of interventions to promote modal shift

\begin{tabular}{|c|c|c|c|c|c|c|}
\hline \multirow[b]{2}{*}{ Study } & \multirow[b]{2}{*}{ Validity score } & \multirow[b]{2}{*}{$\begin{array}{l}\text { Nature of } \\
\text { comparison }\end{array}$} & \multicolumn{4}{|c|}{ Evidence for shift from cars towards walking and cycling* } \\
\hline & & & $\begin{array}{c}\text { Significant positive } \\
\text { effect }\end{array}$ & $\begin{array}{c}\text { Positive effect of } \\
\text { uncertain significance }\end{array}$ & Inconclusive or no effect & $\begin{array}{l}\text { Negative effect of uncertain } \\
\text { significance }\end{array}$ \\
\hline \multicolumn{7}{|c|}{ Targeted behaviour change programmes } \\
\hline Glasgoww1 w2 $^{\text {w1 }}$ & 9 & Controlled & Yes & - & - & - \\
\hline Perth, Australia (TravelSmart) ${ }^{\text {w3-9 }}$ & 7 & Controlled & Yes & - & - & - \\
\hline Frome (TravelSmart pilot) ${ }^{\text {w10 }}$ & 9 & Controlled & - & Yes & - & - \\
\hline Gloucester (TravelSmart pilot) ${ }^{\text {w11 }}$ & 9 & Controlled & - & Yes & - & - \\
\hline Århus $^{\text {w12-14 }}$ & 7 & Uncontrolled & - & Yes & - & - \\
\hline Adelaide $^{\text {w15-18 }}$ & 4 & Uncontrolled & - & - & Yes & - \\
\hline \multicolumn{7}{|c|}{ Publicity campaigns and agents of change } \\
\hline Camden-Islington ${ }^{\mathrm{w} 19}$ & 8 & Controlled & - & - & Yes & - \\
\hline Maidstone $^{\mathrm{w} 20}$ & 7 & Controlled & - & - & Yes & - \\
\hline Phoenix ${ }^{\mathrm{w} 21}$ & 5 & Uncontrolled & - & Yes & - & - \\
\hline Eugene $^{\text {w22 }}$ & 4 & Uncontrolled & - & - & Yes & - \\
\hline \multicolumn{7}{|l|}{ Engineering measures } \\
\hline Delft ${ }^{\text {w23-30 }}$ & 7 & Controlled & - & Yes & - & - \\
\hline 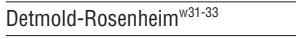 & 6 & Uncontrolled & - & - & - & Yes \\
\hline Stockton ${ }^{1344}$ & 5 & Uncontrolled & - & - & - & Yes \\
\hline $\begin{array}{l}\text { England }(20 \mathrm{mph}(30 \mathrm{~km} / \mathrm{h}) \\
\text { zones) }\end{array}$ & 5 & Uncontrolled & - & - & Yes & - \\
\hline Boston ${ }^{w 38-40}$ & 4 & Uncontrolled & - & Yes & - & - \\
\hline England (bypasses) & 3 & Uncontrolled & - & - & - & Yes \\
\hline \multicolumn{7}{|l|}{ Financial incentives } \\
\hline California (cashing out) $^{\mathrm{w} 41 \text { w/2 }}$ & 8 & Controlled & Yes & - & - & - \\
\hline Trondheim ${ }^{\text {w43 w44 }}$ & 7 & Uncontrolled & - & - & - & Yes \\
\hline \multicolumn{7}{|l|}{ Providing alternative services } \\
\hline San Franciscovi45-47 & 7 & Controlled & - & - & Yes & - \\
\hline Voorhoutw48 $^{\text {tw }}$ & 7 & Uncontrolled & Yes & - & - & - \\
\hline California (telecommuting) $^{\text {w49 }}$ & 4 & Controlled & - & - & - & Yes \\
\hline
\end{tabular}

${ }^{*}$ No studies had significant negative effects.

\section{Targeted behaviour change programmes (six studies of four interventions)}

These programmes aimed to change people's travel behaviour by offering an intervention only to a motivated subgroup of the population or by offering information and advice tailored to people's particular requirements, or both.

The Walk In to Work Out self help package in Glasgow (Scotland) was evaluated in a randomised controlled trial in commuters identified as contemplating or actively preparing to

\section{Calculation of a common primary outcome metric}

We found that studies had used various metrics for expressing data relevant to our primary outcome measure. We could not identify a single common metric with which to synthesise the results of all relevant studies, but where possible we did summarise effects on the overall distribution of transport choices as follows.

We calculated the absolute change in the percentage share of all trips that were made by walking and cycling combined and compared this with the absolute change in the percentage share of all trips that were made by car. If the two changes were in opposite directions, we took the smaller of the two changes and used this to summarise the absolute shift from the car to the physically active modes. For example, if the percentage share of car trips decreased from $50 \%$ to $40 \%$ of all trips, and the percentage share of walking and cycling trips combined increased from $20 \%$ to $25 \%$, we summarised this as a positive modal shift of $5 \%$ of all trips from a baseline share of $20 \%$. If the two changes were in the same direction (if, for example, the public transport share of all trips increased at the expense of car, walking, and cycling trips) we summarised this as a modal shift of zero. change their behaviour. After six months, the intervention group reported an increase in mean time spent walking to work each week 1.93 (95\% confidence interval 1.06 to 3.52) times greater than in people in the control group. ${ }^{\mathrm{w} 1}{ }^{\mathrm{w} 2}$ In the TravelSmart programme, households interested in changing their behaviour were given a tailored selection of resources such as leaflets, timetables, maps, and free trial bus tickets. A controlled repeated cross sectional study of a sample of all households in one area in Perth (Australia) found a positive shift of $5.5 \%$ of all trips $(\mathrm{P}<0.01)$ in the intervention area after six months compared with a $2 \%$ shift towards the car in a neighbouring control area. ${ }^{3-9}$ Subsequent controlled pilots in Frome ${ }^{\mathrm{w10}}$ and Gloucester ${ }^{\mathrm{w11}}$ (England) also found net positive shifts $(3.6 \%$ and $4.4 \%$ respectively).

In Århus (Denmark), volunteer suburban car commuters were given a free bike and bus pass for a year in the Bikebusters programme. In an uncontrolled study, participants reported a positive shift of $25 \%$ of all weekday trips after 11 months. ${ }^{\text {w12-14 }}$ In the Travel Blending programme, households in two areas in Adelaide (Australia) were given tailored feedback on personal travel diaries, supported with information such as timetables or maps. In an uncontrolled panel study, households reported small changes $(1.0 \%$ and $-2.0 \%$, respectively) in walking trips and larger but inconsistent changes in cycling trips after one month. ${ }^{\text {w15-18 }}$

\section{Agents of change and publicity campaigns (four studies)}

These interventions were applied to whole groups of people undifferentiated by motivation or personal travel circumstances. A cluster randomised controlled trial in primary schools in Camden and Islington (London) found that pupils in 10 intervention schools that received one year's input from a school 
travel coordinator were no less likely to travel to school by car than those in control schools (odds ratio $0.98,95 \%$ confidence interval 0.61 to 1.59 ). ${ }^{\text {w19 }}$ In Maidstone (England), a controlled repeated cross sectional study of households on trunk route corridors showed that two years after a publicity campaign on sustainable transport, the only significant change was a decrease in cycling trips in the intervention area $(\mathrm{P}<0.05){ }^{\text {w20 }}$

Drivers responding to an uncontrolled repeated cross sectional telephone survey in Phoenix (Arizona, USA) reported a positive shift of $1 \%$ of commuting journeys seven months after the Clean Air Force campaign to promote not driving to work one day a week. ${ }^{\text {w21 }}$ In the Curb Your Car campaign, transport coordinators organised promotional events and distributed free bus passes at state workplaces in Eugene (Oregon). An uncontrolled repeated cross sectional study found no evidence of a shift in employees' usual mode of travel to work after nine months. ${ }^{\text {w22 }}$

\section{Engineering measures (six studies)}

Repeated cross sectional household studies in Delft (Netherlands; controlled study) and Detmold and Rosenheim (Germany; uncontrolled study) evaluated the effects of improving and extending cycle route networks. In Delft, households in the intervention suburb reported a 3\% increase after three years in the share of all trips made by bike, with no change in the shares for walking or car use; in the control area, the frequency of car trips increased and the frequency of bike trips did not change. A nested panel study found a positive shift of $0.6 \%$ of all trips. ${ }^{\text {w23-30 }}$ In Detmold and Rosenheim, households reported a negative shift of $5 \%$ of all trips (Detmold) and zero shift (Rosenheim) after five years. ${ }^{\text {w31-33 }}$

An uncontrolled repeated cross sectional study in secondary school pupils in Stockton (England) reported a negative shift of $2 \%$ in their usual mode of travel to school 17 months after a new cycle route was opened in the town. ${ }^{\text {w34 }}$ Also in England, traffic restraint schemes were evaluated in uncontrolled studies of 20 miles $(30 \mathrm{~km})$ per hour zones in six urban neighbourhoods and of the Bypass Demonstration Project in six small towns. There was no evidence of a change in travel patterns in a panel study of residents of the 20 miles per hour zones, ${ }^{\text {w35 }}$ and a repeated cross sectional survey of residents of the bypassed towns found a negative shift of $3 \%$ in their main mode of travel to the town centre. $^{\text {w36-37 }}$

Office workers in an uncontrolled repeated cross sectional study in Boston (USA) reported a positive shift of less than $1 \%$ of commuting journeys after the introduction of the downtown auto restricted zone. ${ }^{\text {w38-40 }}$

\section{Financial incentives (two studies)}

A controlled repeated cross sectional study in California evaluated a directive to "cash out" the cost of subsidising workplace parking (by offering at least equivalent subsidies to staff who commute by modes other than driving). Employees at eight intervention workplaces reported a positive shift of $1 \%$ of commuting journeys after one to three years $(\mathrm{P}<0.01)$ compared with no significant change in one control workplace. ${ }^{\mathrm{w} 41 \text { w42 }}$ In Trondheim (Norway), a toll ring was introduced for motor vehicles around the city centre. An uncontrolled household panel study found a negative shift of 2.6\% of all trips after one year. ${ }^{\mathrm{w} 43} \mathrm{w} 44$

\section{Providing alternative services (three studies)}

A controlled repeated cross sectional study of the City CarShare club in San Francisco (USA) found that members were no more likely to report a positive shift after nine months than aspiring members still waiting to join. The share of journeys made by car increased by a greater proportion than the combined walking and cycling mode share did (17.0\% and 3.7\%, respectively). ${ }^{\mathrm{w} 45-47}$

In Voorhout (a commuter town in the Netherlands), an uncontrolled household panel study found a positive shift of $5.0 \%$ of all trips $(\mathrm{P}<0.001)$ one year after the first train station was opened in the town. ${ }^{\mathrm{w} 48}$ A controlled retrospective study of commuters registered with neighbourhood telecommuting centres in California (USA) found a negative shift of $0.2 \%$ on telecommuting days compared with normal commuting days, with a $24 \%$ decrease in reported distance travelled on foot or by bike. $^{\text {w49 }}$

\section{Effects on health (six studies)}

We found robust evidence of effects on health in only two randomised controlled trials of the effects of active commuting in selected volunteers (see table $\mathrm{D}$ on bmj.com). The Walk in to Work Out trial in Glasgow (Scotland) showed significant net increases in sample mean scores on the mental health, vitality, and general health subscales of the SF-36 after six months. ${ }^{\text {w1 }}$ A smaller trial in Tampere (Finland) showed significant net improvements in maximum aerobic power, maximum treadmill time, and heart rate and blood lactate concentrations at submaximal standard workload after 10 weeks. $^{\text {w50 }}{ }^{\text {w51 }}$ We also found data on road traffic incidents and other aspects of community health, but only from small studies of relatively low validity of interventions not shown to be effective in promoting a shift in mode of transport. ${ }^{\text {w34.37 }}$

\section{Social distribution of effects (11 studies)}

Findings on social distribution of effects were generally reported briefly or without the data on which statements were based, or both. The data were insufficient to permit any meaningful synthesis (see table E on bmj.com).

\section{Discussion}

\section{Principal findings}

In this systematic review of interventions to promote a population shift from using cars towards walking and cycling we found evidence from a few relatively well conducted studies that targeted programmes can change the behaviour of motivated subgroups. ${ }^{\text {w1-14 }}$ At a population level (in the main TravelSmart study) this resulted in around 5\% of all household trips being shifted from cars to walking and cycling. Volunteers participating in trials experienced short term improvements in certain measures of health or fitness after taking up active commuting. ${ }^{\mathrm{w} 1}$ w2 w50 w51 Single studies of commuter subsidies ${ }^{\mathrm{w41} \mathrm{w}^{42}}$ and a new train station $^{\mathrm{w} 48}$ have also shown positive shifts of $1 \%$ and $5 \%$ of trips, respectively.

The balance of best available evidence about agents of change, publicity campaigns, engineering measures, and charging road users suggests that they have not been effective in our terms. ${ }^{\text {w19-40 w43 w44 }}$ We also found evidence from single controlled studies that car share $\operatorname{clubs}^{\mathrm{w} 45-47}$ and telecommuting ${ }^{\mathrm{w} 49}$ were not effective; if anything, participation in these interventions was associated with negative effects.

\section{Strengths and weaknesses of the review}

We sought population level evidence to answer a public health question. We therefore searched for a wide range of evidence from diverse sources, making no assumptions about what types of intervention or study design would be relevant, and explicitly considering external validity or transferability (such as the choice of study population) in selecting studies for inclusion. ${ }^{13}$ We may 
still have missed some relevant evidence because of poor indexing in some databases. A common objective of synthesising evidence is to pool results and derive generalisable estimates of effect size, but we could not do this because the interventions and studies we found were heterogeneous.

Few systematic reviews of interventions to improve health have explicitly sought evidence of the social distribution of effects. We did seek such evidence but found that it was limited and often not supported by the citation of actual data.

\section{Strengths and weaknesses of the available evidence}

In general, the most robust evidence of effectiveness was concentrated around interventions targeted at motivated groups of volunteers. Neither these interventions nor their observed effects are necessarily applicable to larger, less selected populations. Many of the other studies were of poor quality or were poorly reported. We found little evidence of how the effects of the interventions were distributed in the population and no good evidence of how an effective population level intervention had influenced any aspect of population health.

We chose to specify a shift in mode of transport between cars and walking and cycling as our key outcome measure, but relatively few primary studies have reported data about this outcome. Some interventions were not primarily designed to achieve this. Others may have been ineffective in our terms but successful in other terms, such as promoting public transport at the expense of other modes or promoting cycling at the expense of walking. Our difficulty in finding relevant evidence may reflect hitherto different priorities in the transport and health policy and research communities. Walking and cycling have long been marginalised in transport planning, and recognition of their potential wider social benefits remains limited. ${ }^{14}$ Emerging findings from contemporary interventions such as the London congestion charge or the National Cycle Network suggest that these may be encouraging walking or cycling, ${ }^{15}{ }^{16}$ but evaluation studies are often not designed to assess effects on important population health determinants such as physical activity.

\section{Implications and unanswered questions}

It is difficult to change longstanding and complex patterns of behaviour so the evidence that some in-depth, targeted interventions have achieved any measurable shift is encouraging. Our findings are consistent with a view that interventions that engage people in a participative process and address factors of personal relevance may be more effective than those that simply aim to raise awareness or impose changes in the physical and economic environments. Some less targeted types of intervention, however, remain to be rigorously evaluated so this view reflects absence of evidence as much as it reflects evidence of absence of effectiveness. ${ }^{17}$

The authors of two studies stated that observed increases in cycling were largely attributable to existing cyclists making more trips. ${ }^{\text {w3-9 }}{ }^{\text {w23-30 }}$ Together with the finding that the best evidence of effectiveness is for targeted behaviour change programmes, this raises the possibility that an apparently "successful" intervention could conceal increasing disparities in levels of physical activity between social groups. This requires further research.

Ecological comparisons show that the proportion of walking and cycling journeys can vary between populations, both between and within countries, by an order of magnitude greater than the population effect size of any intervention included in this review. ${ }^{18-21}$ It may be unrealistic to expect interventions to produce substantial effects in relatively inactive populations without addressing the other, potentially complex reasons for such variations, such as attitudes towards cars and bicycles. Com-

\section{What is already known on this topic}

Transport policies increasingly seek to reduce traffic congestion by discouraging car use and encouraging the use of alternative modes of transport, such as walking and cycling

We lack good evidence either on which interventions are likely to be effective in promoting a shift from using cars towards walking and cycling or on the actual effects of such interventions on population health

\section{What this study adds}

Targeted behaviour change programmes can be effective in changing the transport choices of motivated subgroups, but the social distribution of their effects and their effects on the health of local populations are unclear

Evidence that other types of intervention have been effective is inconsistent, of low validity, based on single highly contextual studies, or non-existent

bining interventions in a genuinely integrated urban transport policy might be more effective, but we currently lack evidence from intervention studies to support this assertion.

Our findings echo Wanless's more general observation that we know relatively little about the likely impact on health of interventions to influence the wider determinants of population health. ${ }^{22}$ Many transport policy interventions constitute natural experiments, in which effects on population health could and should be evaluated using well designed prospective (and, where appropriate, controlled) studies. These studies should use varied methods of evaluation to provide multiple perspectives on the supposed causal relation between a complex intervention and its alleged effects. They should assess changes in physical activity and wellbeing, as well as adverse effects such as injuries and the potential for widening social inequalities in health and determinants of health.

We are grateful to the numerous colleagues who commented on draft versions of our review protocol and reference list. We also thank David Cumming for advice on literature searching and those who provided clarifications and additional information about studies, particularly Solveig Meland, James Ryle, and Julie Whitehouse.

Contributors: DO and MP had the original idea. DO designed the review with input from MP, carried out study selection, data extraction, and critical appraisal and wrote the paper. All authors contributed to the design of the study and writing of the paper. $\mathrm{VH}$ and DO executed the literature search, and ME and MP contributed to study selection, data extraction, and critical appraisal. DO is guarantor for the paper.

Funding: Chief Scientist Office of the Scottish Executive Health Department and the ESRC Evidence Network.

Competing interests: None declared.

Ethical approval: Not required.

1 McCarthy M. Transport and health. In: Marmot M, Wilkinson R, eds. Social determinants of health. Oxford: Oxford University Press, 1999.

2 Morris J. Exercise in the prevention of coronary heart disease: today's best buy in public health. Med Sci Sports Exercise 1994;26:807-14.

3 Dora C. A different route to health: implications of transport policies. BM/ 1999;318:1686-9.

Department for Transport. A new deal for transport: better for everyone. London: Stationery Office, 1998.

5 Secretary of State for Scotland. Travel choices for Scotland. The Scottish integrated transport white paper. Edinburgh: Stationery Office, 1998.

white paper. Edinburgh: Stationery Office, 1998.

$\begin{array}{ll}6 & \text { Carnall D. Cycling and health promotion. BMJ 2000;320:888. } \\ 7 & \text { Roberts I. Congestion charging and the walking classes. BMJ 2003;326:345-6. }\end{array}$

8 Petticrew M. Presumed innocent: why we need systematic reviews of social policies. $A m$ J Prev Med 2003;24(3 suppl):2-3. 
9 Morrison D, Petticrew M, Thomson H. What are the most effective ways of improving population health through transport interventions? Evidence from systematic reviews. J Epidemiol Community Health 2003;57:327-33.

10 Clarke M, Oxman A, eds. Cochrane reviewers' handbook 4.1.5. Oxford: Update Software, 2002.

11 NHS Centre for Reviews and Dissemination. Undertaking systematic reviews of research on effectiveness: CRD report no. 4. York: NHS Centre for Reviews and Dissemination, 2001.

12 Egan M, Petticrew M, Ogilvie D, Hamilton V. New roads and human health: a systematic review. Am J Public Health 2003;93:1463-71.

3 Rychetnik L, Frommer M, Hawe P, Shiell A. Criteria for evaluating evidence on public health interventions. J Epidemiol Community Health 2002;56:119-27.

14 House of Commons Health Committee. Obesity: third report of session 2003-04. London: Stationery Office, 2004

15 Transport for London. Congestion charging central London. Impacts monitoring: second annual report, April 2004. London: Transport for London, 2004

16 Sustrans. The National Cycle Network route user monitoring report to end of 2003. Bristol: Sustrans, 2004.

17 Alderson P. Absence of evidence is not evidence of absence. BMJ 2004;328:476-7. 18 ADONIS Project. Best practice to promote cycling and walking. Copenhagen: Road Directorate, Danish Ministry of Transport, 1998.

19 Jacobsen P. Safety in numbers: more walkers and bicyclists, safer walking and bicycling. Inj Prev 2003;9:205-9.
20 Commission for Integrated Transport. European best practice in delivering integrated transport-key findings. London: Commission for Integrated Transport, 2001.

21 Scottish Executive. Transport across Scotland: some Scottish Household Survey results for parts of Scotland. Edinburgh: Scottish Executive, 2001. (Statistical Bulletin Trn/2001/4.)

22 Wanless D. Securing good health for the whole population: final report. London: HM Treasury, 2004.

(Accepted 4 August 2004)

doi 10.1136/bmj.38216.714560.55

MRC Social and Public Health Sciences Unit, University of Glasgow, Glasgow G12 8 RZ

David Ogilvie MRC fellow

Matt Egan social scientist

Mark Petticrew associate director

Centre for Digital Library Research, University of Strathclyde, Glasgow G1 1XH

Val Hamilton research coordinator

Correspondence to: D Ogilvie d.ogilvie@msoc.mrc.gla.ac.uk 